\title{
Feasibility of Modifying Existing Chemistry Demonstrations by Using Substitute Materials
}

\author{
Dane Mykel M. Quiambao ${ }^{1 *}$, Armando M. Guidote Jr. ${ }^{1,3}$, Rhodora F. Nicdao ${ }^{2}$ \\ ${ }^{1}$ Department of Chemistry, Loyola Schools, Ateneo de Manila University, Katipunan Ave. Loyola Heights, \\ Quezon City, Philippines 1108 \\ ${ }^{2}$ Department of Education, Loyola Schools, Ateneo de Manila University, Katipunan Ave. Loyola Heights, \\ Quezon City, Philippines 1108 \\ ${ }^{3}$ Philippine Institute of Pure and Applied Chemistry (PIPAC), Ateneo de Manila University Campus, Katipunan \\ Ave. Loyola Heights, Quezon City, Philippines 1108
}

*Author to whom correspondence should be addressed; email: qdanemykel@gmail.com

\begin{abstract}
This study aimed to reiterate the use of Chemistry demonstrations as effective teaching tools to students while addressing some of its drawbacks, which discourages teachers from doing them such as cost and safety. Four chosen existing Chemistry demonstrations (Blue Bottle Experiment, Copper Sulfate Experiment, Blown Away, Dancing Flames) were modified by using substitute reagents, which are more accessible, relatively safer, and at lower cost. These demonstrations were chosen based on how easily the substitute reagents will be obtained. Afterwards, with the permission of a private junior high school, they were presented to a group of Grade 9 students of their choosing. The students were asked to evaluate each demonstration using a Likert scale-based questionnaire. This questionnaire rates each demonstration in terms of aesthetics, the materials and procedure done, effectiveness to explain certain Chemistry topics, safety, and the students' overall judgment regarding the use of demonstrations as teaching tools. By converting their evaluation to quantitative values, the demonstrations scored high in all major categories. With this, it is highly recommended to explore other Chemistry demonstrations for possible modifications, which can be integrated in lecture classes.
\end{abstract}

Keywords: Chemistry demonstrations; Introductory Chemistry; Likert scale-based questionnaire

\section{INTRODUCTION}

In the field of Science, Chemistry has always been one of the more exciting sciences to learn about because different products and phenomena that we see in real life can be explained. It is also where the other branches of Science such as Biology and Physics come together, which makes it all the more interesting. 
But at the same time, this makes it one of the more complicated sciences both to learn and to teach. As a student, one of the most challenging parts of learning Chemistry is being able to understand the concepts from the macro level. The fact that Chemistry primarily deals with particles that cannot be seen by the naked eye and that there are a lot of things going on makes it even more difficult. This is why Chemistry courses, or Science in general, should be supplemented by laboratory classes (Hered, 1950). But due to lack of facilities and equipment especially in public schools in developing countries, most students are not able to experience that. This is more difficult to teachers too because with the lack of lab classes, they resort to teaching by the book and rely on visual aids such as pictures and videos. What is worse is that some teachers cannot afford visual aids due to the lack of facilities and financial problems. This might decrease the students' interest in the subject and only a few or even none would want to pursue a career in the field in the future.

One of the alternatives to laboratory classes that can be done is by doing demonstrations wherein instead of just watching an experiment during a lecture, the teacher executes the experiment while the rest of the class observes. One of the skills, which they can still develop through this even without the typical laboratory experiments is problem-solving skills (Meyer et al., 2003). They will be encouraged to ask questions about what happened and even draw inferences of what they think happened during the demonstration. Their observational skills will also be honed just like in a typical laboratory setting ("Chemical Demonstrations in the Classroom", n.d.) wherein they will learn to be conscious of the different changes happening in the demonstration. This will also result in a constant student-teacher interaction as compared with a typical lecture wherein the professor teaches in almost a monologue. "Teaching methods that involve students and teachers are proven to be better," (Zejnilagić-Hajrić \& Nuic, 2015) because they work together to make the learning experience more effective. A method of teaching that encourages team learning and student-led discussions (such as chemistry demonstrations), as compared to a normal lecture teaching, favors better performance of the students (Carpenter, 2006) since it encourages more participation in class boosting their self-confidence.

Despite this, using this method is still not widely used due to various reasons. One reason is because it is time-consuming (Walton, 2002) considering that the bulk of their time is allotted for preparation of their lesson plans (Meyer et al., 2003). Time is not only needed in preparing the demonstration, but it is also needed in trying-out the demonstration, preparing the necessary points that the educator wants to emphasize, and looking out for safety precautions that needs to be observed. Another hindrance is the misconception that demonstrations need expensive kits or materials (Meyer et al., 2003).

This study aims to modify pre-existing Chemistry demonstrations that can address the reasons stated above by using substitute reagents, which are better than the original in terms of accessibility, safety, and cost. Necessary revisions to the procedures were done to replicate the result of each original demonstration. Afterwards, as a supplement to the study, these demonstrations were presented to a group of high school students from a private junior high school. Each demonstration was evaluated using a Likert scale-based questionnaire which is based on the given criteria.

The use of demonstrations in lectures has been supported by a lot of studies worldwide over the past years (Walton, 2002; Meyer et al., 2003; Sullivan, 1990; O’ Brien, 1991). A study conducted by Paul Walton, a chemistry faculty member at the University of York involved getting responses from freshmen undergraduate students who attended an Acids and Bases lecture with integrated demonstrations. They were given a set of statements and were asked if they agree to each or not. The results showed that $87 \%$ (either totally or partially) agreed that demonstrations helped them 
understand the theories behind the lesson. Moreover, 95\% (either totally or partially) agreed that the demonstrations kept their interest during the lecture (Walton, 2002).

Another study was conducted by Ophardt, Applebee, and Losey in 2005, which involved students from nonscience major courses in Elmhurst College. In their laboratory course, they performed various chemistry demonstrations in class and eventually in front of students from a local elementary school. The students were then asked to give their thoughts on the course in terms of their learning objectives and comparing it with the traditional laboratory setting. Their questionnaires have statements, which they rate in a 1-5 range, with 5 being the highest. The results showed high average scores when talking about their learning objectives. These include learning basic chemistry concepts (score: 4.67) and strengthening the interest in science (score: 4.28). Comparing with traditional science labs, students preferred their demonstration-focused lab. Areas of question include interest in activities performed on a given day (score: 4.42) and freedom to learn at their own pace (score: 4.00) (Ophardt, et.al., 2005). The latter result proves that chemistry demonstrations can help educators and adapt to the students' different learning styles (Meyer et al., 2003).

\section{METHODS}

Existing chemistry demonstrations were modified by replacing the reagents with more accessible materials with lower cost. The chemistry demonstrations were chosen based on the availability, accessibility, and affordability of possible substitutes, particularly in the Philippines. Since all the demonstrations are adequately documented in various sources, these became the visual models of what the demonstrations (experiments) should look like. They became the basis in possible changes in formulation of the materials, comparing the original and the substitute.

As a supplement to the study, the demonstrations were presented to a group of 24 junior high school students in a private junior high school. The sample size and respondents were chosen by the school itself based on their schedule as well as the relevance of the prepared demonstrations to their current curriculum. Afterwards, they were given a Likert scale-based questionnaire where they were asked to evaluate the presented demonstration (See Supporting Information A). This work was granted a Validation of Exemption from Review by the Ateneo de Manila University Research Ethics Office (UREO).

The 10-item questionnaire is based on five major categories that was deemed important in evaluating a Chemistry demonstration. Items \# 1 and 6 fall under the Attention Getting category, which rates how the demonstration got the students' attention visually. The second category is Technical Procedure (items \# 2 and 4), which assesses the demonstration materials and procedure. This also includes accessibility and difficulty. The third category is Lecture Value (items \# 3, 5 and 7), which deals with the effectiveness of the demonstrations to the respective Chemistry topics that they were connected to. Fourth category is Safety (item \# 8), which rates the overall safety of each demonstration, i.e., if it is possible to do each demonstration outside the laboratory and if it is without any extreme danger to the students and teacher. The last category is Overall Judgment (item \# 9 and 10), which rates the overall reaction of the students to the demonstrations. It rates how helpful the demonstrations can be if they are applied as teaching tools during lectures. 
The following are the modified demonstrations:

1. Blue Bottle Experiment - this involves the reduction-oxidation reaction of dextrose and methylene blue in a basic solution (See Supporting Information B);

2. Copper Sulfate Experiment - this is a reversible reaction which involves the dehydration of copper (II) sulfate (See Supporting Information C);

3. Blown Away - this is a precipitation reaction between calcium hydroxide and carbon dioxide (See Supporting Information D); and

4. Dancing Flames - this is a single displacement reaction between copper (II) sulfate and aluminum in acid (See Supporting Information E).

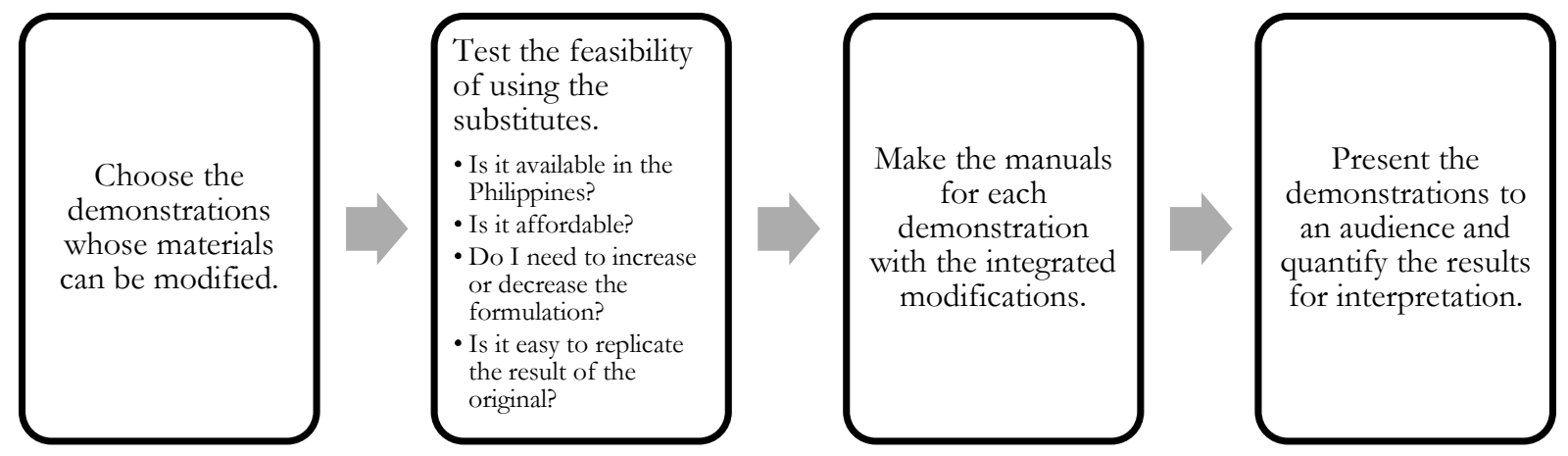

Figure 1. Procedural Diagram for the Study

\section{RESULTS AND DISCUSSION}

The main reagents of each demonstration as written and published in online journals and respected websites are shown in Table 1 indicating as well the list of the substitute materials and their cost of purchase at the time of the study. Using these substitutes, the results of the original Chemistry demonstrations were replicated with some modifications in the procedure.

The Likert scale responses were translated into a numerical value using the criteria suggested by Joshi et al. (2015) where the Likert scale can be treated as an interval scale, which is usually a five or seven-point scale ("Likert Scale | Simply Psychology," n.d.). The mean score of each major category of each experiment was obtained. These are the 'interval estimates' (Joshi et al., 2015), which were then fit to a score range. Each were given a corresponding interpretation to obtain a qualitative result. Afterwards, these mean scores were combined to report all demonstrations as one in each of the categories.

Table 2 showed that all the presented Chemistry demonstrations afforded positive results in all categories, with the mean scores equivalent to the Very Good to Excellent range. Supported by the low standard deviations measured from all categories, it can be inferred that the students enjoyed the demonstrations and that they saw the demonstrations being beneficial in understanding the Chemistry topics. 
Table 1. Main reagent list of the experiments and its substitute materials

\section{Original Experiment Materials}

\section{Experiment Source: Royal Society of Chemistry ("The 'Blue} Bottle' Experiment”, n.d.)

Potassium hydroxide solid
Source: Flinn Scientific ("Blue Bottle Experiment", n.d.)

Potassium hydroxide, solid

Liquid sosa

Substitute

Price of Substitute

PHP 92.50

(USD 1.86)

$(500 \mathrm{~mL})$

I. Blue Bottle Glucose (dextrose), solid

Dextrose, solid Experiment

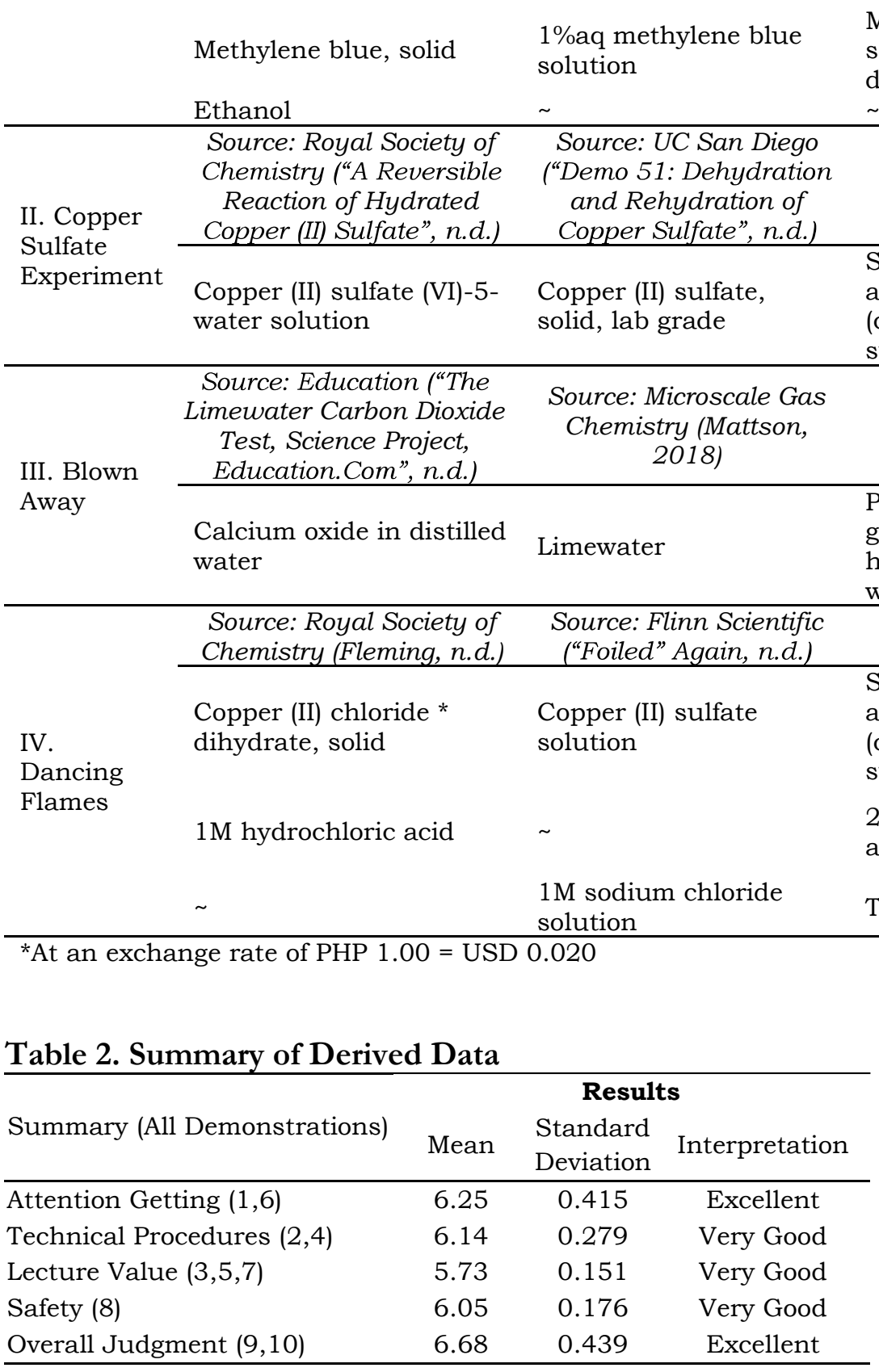

Dextrose powder

(dog supplement)

PHP 120.00

(USD 2.41)

(300g)

Methylene blue PHP 25.00 solution (fish tank (USD 0.50) disinfectant)

(120mL)

Substitute

Price of Substitute

Swimming pool algaecide powder (chelated copper sulfate)

PHP 550.00

(USD 11.05)

(1kg)

Substitute Price of

Substitute

Pickling lime (food grade calcium hydroxide) in tap

PHP 100.00 water

(USD 2.01)

(500g)

\begin{tabular}{lr}
\multicolumn{1}{c}{ Substitute } & $\begin{array}{r}\text { Price of } \\
\text { Substitute }\end{array}$ \\
\hline $\begin{array}{l}\text { Swimming pool } \\
\text { algaecide powder } \\
\text { (chelated copper }\end{array}$ & $\begin{array}{r}\text { PHP 550.00 } \\
\text { (USD 11.05) } \\
\text { sulfate) }\end{array}$ \\
$28 \%$ muriatic & PHP 49.50 \\
acid & (USD 0.99) \\
& $(100 \mathrm{~kL})$
\end{tabular}

Table salt 
These results support the studies regarding Chemistry demonstrations as helping to "engage students with chemistry itself," (Meyer et al., 2003). For instance, Attention Getting has a mean score of 6.25. The students thus agree that the use of Chemistry demonstrations in general draws the students' attention, which helps build their interest in the topic. This result is similar to Walton's study, which stated that $95 \%$ of the surveyed students said that demonstrations kept their interest in the lecture (Walton, 2002). On the other hand, Technical Procedures (score: 6.14) and Safety (score: 6.05) having high mean scores can address the hesitations the educators have in doing demonstrations as highlighted in this study. Addressing the safety and accessibility concerns by using cheaper and safer substitute reagents suggests strong potential of these experiments for easy integration to lesson plans and curricula. The feasibility of the modified experiments using substitute materials have been successfully demonstrated to achieve its purpose in reinforcing a topic in Chemistry.

\section{CONCLUSION}

The study was successful in modifying existing Chemistry demonstrations by using substitutes that are more accessible, relatively safer, and at a lower cost. With some modifications in the procedure, the end result of each original demonstration was replicated. The Chemistry demonstrations were evaluated with positive results in all categories. This shows that the modified selected demonstrations can be used with confidence. The positive feedback also addresses, and possibly removes, some underlying reservations such as cost and safety in allowing students to do the experiments. In general, this study can help further push and encourage the use and integration of Chemistry demonstrations in school curricula today.

\section{REFERENCES}

A reversible reaction of hydrated copper(II) sulfate [Internet]. RSC Education. [cited 2020 Feb 5]. Available from: https://edu.rsc.org/resources/a-reversible-reaction-of-hydrated-copperiisulfate/437.article

Blue Bottle Experiment [Internet]. [cited 2018 Jul 20]. Available from: https://www.flinnsci.com/blue-bottle-experiment/dc91536/

Carpenter J. Effective Teaching Methods for Large Classes. Journal of Family and Consumer Sciences Education. 2006 Jan 1; 24:13. https://natefacs.org/Pages/v24no2/v24no2Carpenter.pdf

Chemical Demonstrations in the Classroom [Internet]. [cited 2018 May 18]. Available from: http://bradley.bradley.edu/ campbell/elishapaper.htm

Demo 51: Dehydration and Rehydration of Copper Sulfate [Internet]. [cited 2020 Feb 5]. Available from: https://www-chem.ucsd.edu/undergraduate/teaching-labs/demos/demo51.html

Fleming D. Dancing flames [Internet]. RSC Education. [cited 2020 Feb 5]. Available from: https://edu.rsc.org/exhibition-chemistry/dancing-flames/2000045.article

Foiled Again [Internet]. [cited 2020 Feb 5]. Available from: https://www.flinnsci.com/foiledagain/dc95000/

Hered W. Function of the lecture demonstration in science education [Internet]. Division of Chemical Education; 1950 [cited 2020 Jul 4]. Available from: https://pubs.acs.org/doi/pdf/10.1021/ed027p542 
Joshi A, Kale S, Chandel S, Pal D. Likert Scale: Explored and Explained. Br J Appl Sci Technol. 2015 Jan 10;7(4):396-403. https://doi.org/10.9734/BJAST/2015/14975

Likert Scale Definition, Examples and Analysis | Simply Psychology [Internet]. [cited 2019 Apr 29]. Available from: https://www.simplypsychology.org/likert-scale.html

Mattson B. Microscale Gas Chemistry. Educ Quím. 2018 Aug 25;16(4):514. https://doi.org/10.22201/fq.18708404e.2005.4.66089

Meyer LS, Panee D, Schmidt S, Nozawa F. Using Demonstrations to Promote Student Comprehension in Chemistry. J Chem Educ. 2003 Apr 1;80(4):431. https://doi.org/10.1021/ed080p431

O'Brien T. The science and art of science demonstrations. J Chem Educ. 1991 Nov 1;68(11):933. https://doi.org/10.1021/ed068p933

Ophardt CE, Applebee MS, Losey EN. Chemical Demonstrations as the Laboratory Component in Nonscience Majors Courses. An Outreach-Targeted Approach. J Chem Educ. 2005 Aug 1;82(8):1174. https://doi.org/10.1021/ed082p1174

Sullivan DM. A program of science demonstrations by college students. J Chem Educ. 1990 Oct 1;67(10):887. https://doi.org/10.1021/ed067p887

The 'blue bottle' experiment [Internet]. RSC Education. [cited 2020 Feb 5]. Available from: https://edu.rsc.org/resources/the-blue-bottle-experiment/729.article

The Limewater Carbon Dioxide Test | Science project | Education.com [Internet]. [cited 2020 Feb 5]. Available from: https://www.education.com/science-fair/article/gas-sniffers/

Walton PH. On the use of chemical demonstrations in lectures. University Chemistry Education. 2002 May;6(1):22-7. https://www.researchgate.net/publication/242321215 On the use of chemical demonstratio ns in lectures

Zejnilagić-Hajrić M, Nuic I. Demonstration in Teaching Chemistry: The Case of Two HighSchools from Sarajevo Canton. Celal Bayar University Journal of Science. 2015 Dec 1;11. https://doi.org/10.18466/cbujos. 72490 


\section{SUPPORTING INFORMATION A: : Likert Scale}

As part of the reported results of the current study, the principal investigator would like you to answer this questionnaire about the chemistry demonstration that you have watched. Please answer as objectively as you can. Rest assured that only the principal investigator will see your individual responses and you will not be asked for any personal information.

Please check the box which describes your response to the following observations.

Note: The term "chemistry demonstration" refers to the experiment presented, not the whole session.

\begin{tabular}{|c|c|c|c|c|c|c|c|}
\hline $\begin{array}{l}\text { The chemistry } \\
\text { demonstration... }\end{array}$ & $\begin{array}{l}\text { Strongly } \\
\text { Disagree }\end{array}$ & Disagree & $\begin{array}{l}\text { Slightly } \\
\text { Disagree }\end{array}$ & Neutral & $\begin{array}{l}\text { Slightly } \\
\text { Agree }\end{array}$ & Agree & $\begin{array}{l}\text { Strongly } \\
\text { Agree }\end{array}$ \\
\hline $\begin{array}{l}. . \text { was aesthetically } \\
\text { pleasing. }\end{array}$ & & & & & & & \\
\hline $\begin{array}{l}. . \text { was easy to do and the } \\
\text { materials were } \\
\text { accessible. }\end{array}$ & & & & & & & \\
\hline $\begin{array}{l}. . \text { was in line with the } \\
\text { topic/s that it was } \\
\text { discussed into. }\end{array}$ & & & & & & & \\
\hline $\begin{array}{l}. . \text { was poorly executed } \\
\text { and hard to follow. }\end{array}$ & & & & & & & \\
\hline $\begin{array}{l}. . \text { made the related topic } \\
\text { more confusing. }\end{array}$ & & & & & & & \\
\hline $\begin{array}{l}. . \text { was boring and did } \\
\text { not catch my attention. }\end{array}$ & & & & & & & \\
\hline $\begin{array}{l}\text {.. helped me understand } \\
\text { the related topic better. }\end{array}$ & & & & & & & \\
\hline $\begin{array}{l}. . \text { is safe to do outside } \\
\text { the lab and its safety } \\
\text { precautions were laid } \\
\text { out well. }\end{array}$ & & & & & & & \\
\hline $\begin{array}{l}\text { Chemistry } \\
\text { demonstrations are } \\
\text { helpful tools and should } \\
\text { be integrated in lectures. }\end{array}$ & & & & & & & \\
\hline $\begin{array}{l}\text { Presenting Chemistry } \\
\text { demonstrations make } \\
\text { the lecture more } \\
\text { exciting and interesting. }\end{array}$ & & & & & & & \\
\hline
\end{tabular}

Other comments/suggestions: 


\title{
SUPPORTING INFORMATION B Experiment 1: Blue Bottle Experiment
}

\author{
Related topic/s: Redox Reactions
}

Objective: to visualize an example of a redox reaction through color change

\section{Materials}

$5 \mathrm{~g}\left(\sim 1 \frac{1}{2} \mathrm{tsp}\right)$ dextrose powder (food supplement for dogs)

$3 \mathrm{~mL}(\sim 1 \mathrm{tsp})$ liquid sosa ( $\mathrm{NaOH}$ solution)

5 to 7 drops methylene blue (sold in pet shops)

$500 \mathrm{~mL}$ plastic bottle

Safety

- Use gloves in handling the $\mathrm{NaOH}$ solution and methylene blue.

- Make sure that the plastic bottle used does not have any holes.

Procedure

1. Dissolve $5 \mathrm{~g}$ dextrose powder in $300 \mathrm{~mL}$ water in the plastic bottle.

2. Add $3 \mathrm{~mL} \mathrm{NaOH}$ solution and shake.

3. Mix in $1 \mathrm{~mL}$ methylene blue and leave to settle.

\section{Explanation}

Different reactions are taking place during the color change as seen below but the more important reaction is the reduction and oxidation of methylene blue. When the bottle turns blue to colorless, methylene blue is reduced by the dextrose powder through its enediolate anion in alkaline solution to produce methylene white $(\mathrm{MBH})$ which is another name for reduced methylene blue. On the other hand, when the bottle turns colorless to blue, methylene white $(\mathrm{MBH})$ is oxidized by oxygen inside the bottle (See 4-5 in the figure) (Anderson et al., 2012).

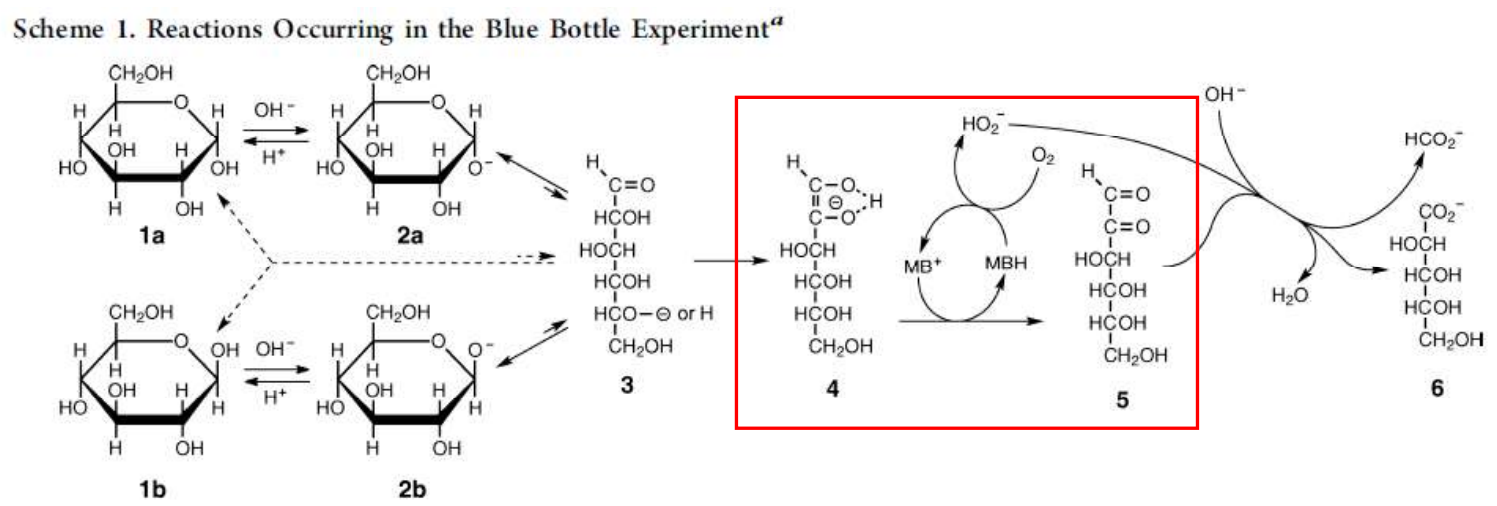

${ }^{a}$ 1a, $\alpha$-D-glucopyranose; 1b, $\beta$-D-glucopyranose; 2a, $\alpha$-D-glucopyranosyloxy anion; $2 \mathrm{~b}, \beta$-D-glucopyranosyloxy anion; 3 , open chain form of glucose; 4, enediolate anion; 5, D-arabino-hexos-2-ulose (glycosulose, open chain form); 6, D-arabinonate anion; $\mathrm{MB}^{+}$, methylene blue; $\mathrm{MBH}$, methylene white; $\mathrm{HO}_{2}{ }^{-}$, hydroperoxide anion; $\mathrm{HCO}_{2}^{-}$, formate anion.

To put it simply, In prep: glucose $+\mathrm{MB}^{+}$(blue) $\rightarrow$ glucosone $+\mathrm{MBH}$ (clear)

In shaking: $\mathrm{MBH}$ (clear) $+\mathrm{O}_{2}(\mathrm{~g}) \rightarrow \mathrm{MB}^{+}$(blue) $+\mathrm{HO}_{2}^{-}$ After oxygen exhaustion: $\mathrm{MB}^{+}$(blue) $\rightarrow \mathrm{MBH}$ (clear) 
Disposal

Since all reagents used are diluted, the mixture can be poured down the sink in running water. Rinse the plastic bottle first before throwing it in the recycle bin.

\section{Documentation}

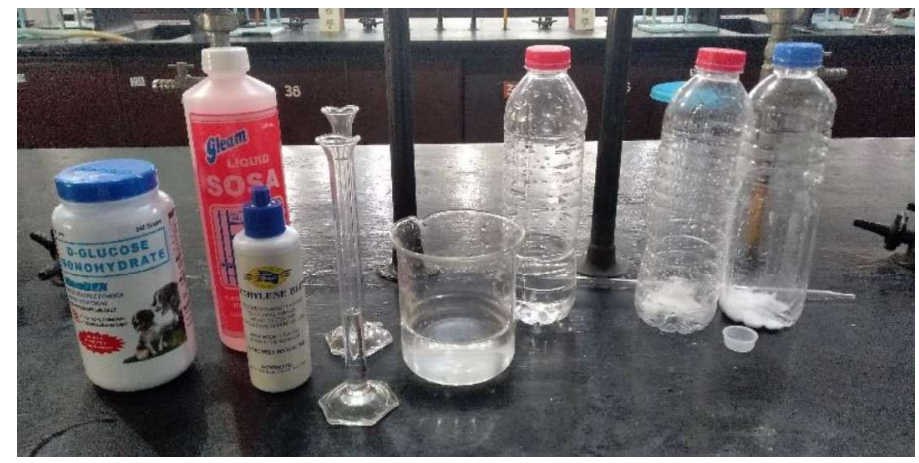

Materials used

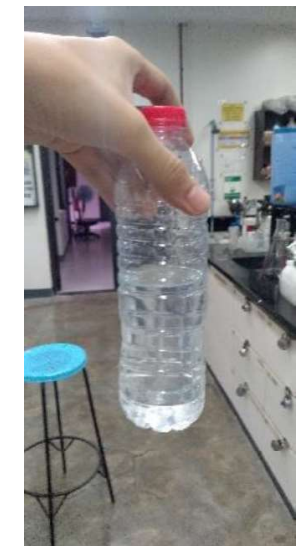

Blue Bottle in idle

\section{Reference}

1. Anderson L, Wittkopp SM, Painter CJ, Liegel JJ, Schreiner R, Bell JA, et al. What Is Happening When the Blue Bottle Bleaches: An Investigation of the Methylene Blue-Catalyzed Air Oxidation of Glucose. J Chem Educ. 2012 Oct 9;89(11):1425-31. 
Related topic/s: Reversible Reactions

Objective: to visualize the reversible activity of a chemical reaction

Materials

- Chelated copper sulfate/pool algaecide (sold in hardware stores)

- Test tube and test tube holder / spoon

- Medicine dropper

- Water

- Makeshift burner

- 3 empty soda cans

- Iron nail and hammer

○ Scissors

- Small knife

- Long nose pliers

○ Ethyl alcohol

○ Tongs

Safety

- Be careful in using the knife.

- In heating up with the test tube, make sure that its mouth is away from you and the audience.

- Always keep your eyes on the burner when it is lighted. Make sure that no combustible materials are surrounding the burner which may catch fire.

Procedure

A. Making the makeshift burner (Lee Yu et al., 2015)

1. Cut two of the three cans two inches from the base. These will serve as the base and cover of the burner.

2. Cut the ends of the third can, leaving about three inches of the body, and cut along its height. This will serve as the support.

3. With one of the two cans that are cut two inches from the base, trace the inner edges of its base with a knife. Puncture a hole using a nail and use the long nose pliers to cut through the base and pull it out.

4. Staple the ends of the support to form a cylinder with a diameter equal to the rim of the base.

5. Place the cover upside down over the base. Puncture pinholes along the top frame using a small nail.

6. To light it up, half-fill the burner with ethyl alcohol and use matches. To be safe, use tongs in pointing the lighted matchstick to the solution.

B. Demonstration

1. Add chelated copper sulfate in the test tube.

2. Using the test tube holder, hold the test tube at the burner. Make sure that the mouth of the test tube is away from you. Observe what happens. 
3. Afterwards, wait for a few seconds for the powder to cool down.

4. Again, with the mouth of the test tube away from you and the audience, slowly put several drops of water but not too much to avoid making it a mixture. Observe what happens.

5. You may also use a spoon instead of a test tube to hold the chelated copper sulfate.

Note: The time it takes to change its color completely depends on the amount of copper sulfate used.

\section{Explanation}

The following reversible reaction is as follows:

$\mathrm{CuSO}_{4} * 5 \mathrm{H}_{2} \mathrm{O}(\mathrm{s})$ (pale blue solid) $\rightleftharpoons \mathrm{CuSO}_{4}(\mathrm{~s})$ ("dirty" white solid) $+5 \mathrm{H}_{2} \mathrm{O}(\mathrm{l})$

Because it is a reversible reaction, we can see that we are able to visualize the original reactants and the direction of the reaction. In the experiment, heating up the chelated copper sulfate colored blue evaporates the water thus making it colored white. On the other hand, adding drops of water to the heated copper sulfate changes its color back to blue (Nuffield Foundation and Royal Society of Chemistry).

\section{Disposal}

- Since the copper sulfate is still primarily solid, you may dispose it in the trash bin. Otherwise, you may dissolve it in water and pour in the sink. For the other materials, you may throw them in the trash bin.

- For the burner, make sure that the fire has been put out before throwing it away. You may do this by covering the burner. The burner can be reused so you may want to keep it.

\section{Documentation}

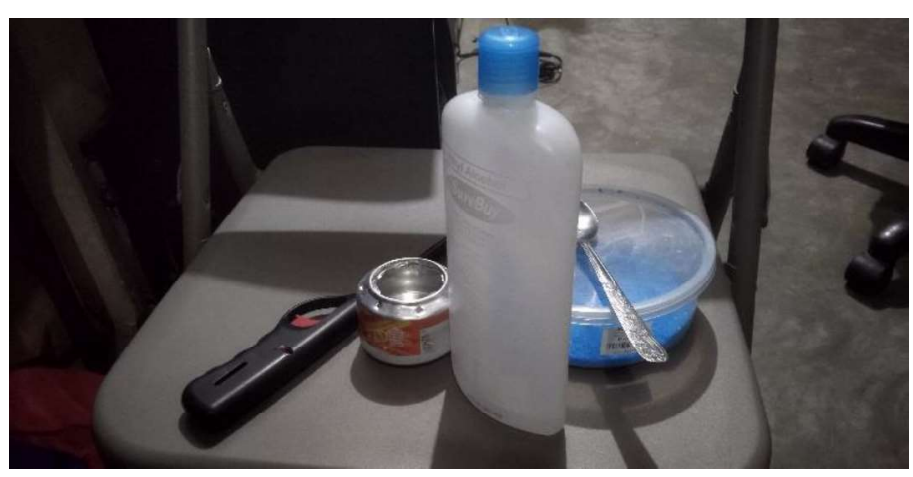

Materials used
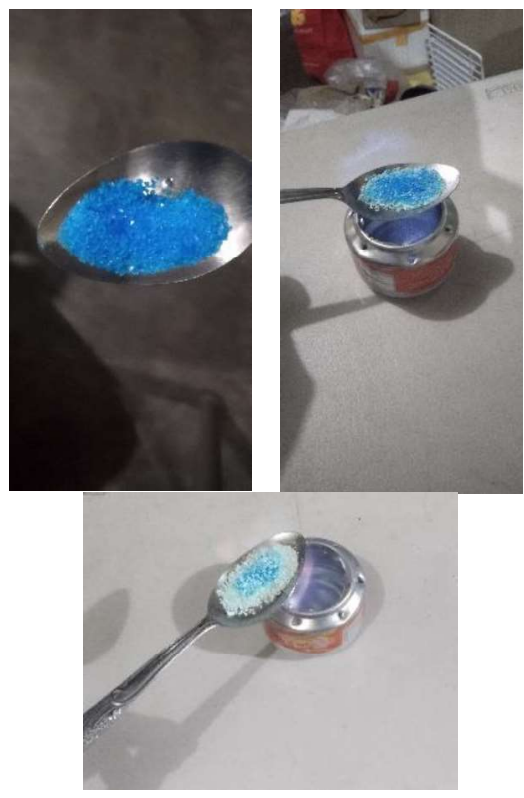

Gradual discoloration of copper(II) sulfate 


\section{References}

1. Lee Yu HL, Domingo PN, Yanza ERS, Guidote AM. Making a Low-Cost Soda Can Ethanol Burner for Out-of-Laboratory Flame Test Demonstrations and Experiments. J Chem Educ. 2015 Jan 13;92(1):127-8.

2. A reversible reaction of hydrated copper(II) sulfate [Internet]. RSC Education. [cited 2020 Feb 5]. Available from: https://edu.rsc.org/resources/a-reversible-reaction-of-hydrated-copperiisulfate/437.article 


\section{SUPPORTING INFORMATION D Experiment 3: Blown Away}

Related topic/s: Formation of precipitates, single displacement reactions

Objectives:

- To demonstrate one of the main features of a chemical change which is the formation of a precipitate

- To visualize an example of a double displacement reaction

Materials

- $\quad 3 g$ ( 1tsp) pickling lime (food grade calcium hydroxide)

- Small cup (plastic or glass)

- Drinking straw

- Small spoon (for scooping the calcium hydroxide)

- $500 \mathrm{ml}$ plastic bottle

Safety

- Do not touch the calcium hydroxide with your bare hands. Use a spoon to scoop. To be safer, use gloves when doing the demonstration.

- Be careful not to suck in the liquid with the straw. Since it is food grade calcium hydroxide, it is generally safe when ingested at a small quantity.

Procedure

A. Before demonstration

1. Dissolve $3 \mathrm{~g}$ calcium hydroxide/pickling lime in water.

2. Pour to a $500 \mathrm{ml}$ plastic bottle and fill. Let it set for 24 hours.

3. Take the liquid. This is what you will use in the demonstration.

B. Demonstration Proper

1. Put some of the liquid in a glass. Blow into it using the straw until a change occurs. Observe.

\section{Explanation}

This experiment involves the double displacement reaction of calcium hydroxide and carbon dioxide from your breath:

$\mathrm{Ca}(\mathrm{OH})_{2}(\mathrm{~s})+\mathrm{CO}_{2}(\mathrm{~g}) \rightarrow \mathrm{CaCO}_{3}(\mathrm{~s})+\mathrm{H}_{2} \mathrm{O}(\mathrm{l})$.

As you blow into the solution, more calcium carbonate is produced which is causing the solution to cloud up and eventually turn white.

\section{Disposal}

- The end solution may be thrown in the sink with running water. The rest of the materials may be thrown in the trash bin. 


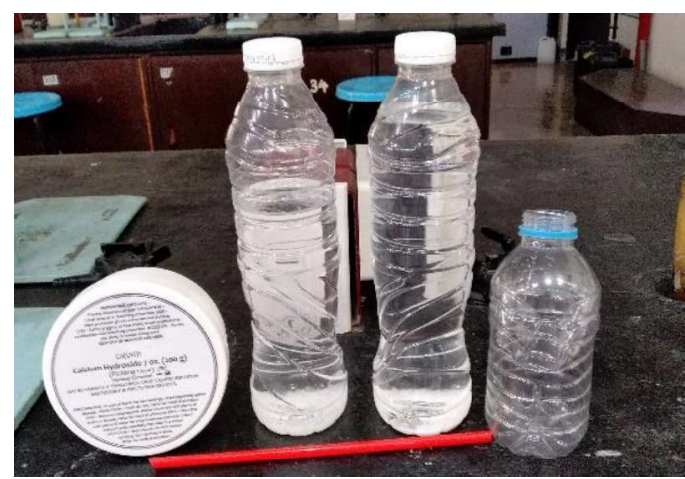

Materials used
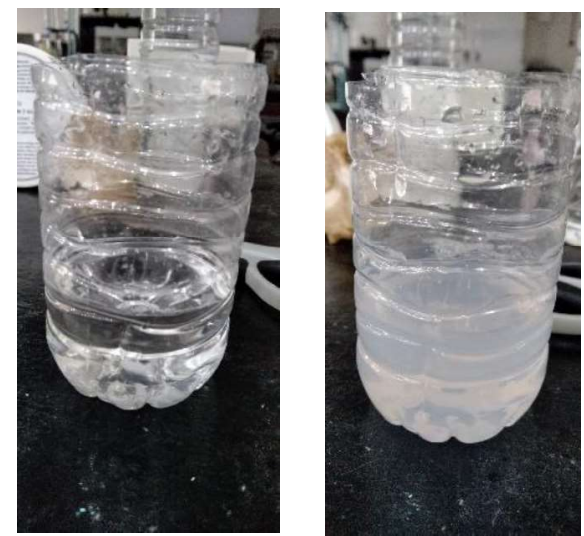

Precipitation of calcium carbonate

\section{Reference}

1. The Limewater Carbon Dioxide Test | Science project | Education.com [Internet]. [cited 2019 Mar 13]. Available from: https://www.education.com/science-fair/article/gas-sniffers/ 
Related topic/s: Reactivity series, single displacement reactions, reduction-oxidation reactions, electrochemical reactions

Objectives:

- To demonstrate an example of a single displacement reaction

- To demonstrate the reactivity of aluminum

Materials

- $5 \mathrm{~g}$ ( $\sim 1 \mathrm{tsp})$ copper (II) sulfate/chelated copper sulfate-based pool algaecide

- $50 \mathrm{~mL}(\sim 10 \mathrm{tsp})$ muriatic acid

- $1250 \mathrm{~mL}$ Erlenmeyer flask (or any heat-resistant container with a long neck)

- Table salt

- Water

- Mixing containers

- Matches/lighter

Safety

- Be careful in lighting up the solution. Make sure that no combustible materials are surrounding the setup which may catch fire. Use goggles for safety.

- When pointing the fire at the flask, make sure that you and your audience are not too close.

- For safety, use gloves especially when dealing with muriatic acid. If it spills on your skin, wash affected area with running water.

Procedure

1. Cut aluminum foil about $20 \mathrm{~cm}$ long and a width as long as the base of the flask. Roll it loosely and put it inside the flask. Make sure that it is sitting on its side at the base of the flask. You can use the splint to push it down almost flat in the flask.

2. Dissolve 1 teaspoon $(\sim 5 \mathrm{~g})$ table salt in $50 \mathrm{~mL}$ water. Set aside.

3. Dissolve the copper (II) sulfate in muriatic acid. Add half of the $\mathrm{NaCl}$ solution and 2 teaspoons $(\sim 10 \mathrm{~mL})$ water.

4. Pour this solution onto the flask with the aluminum foil. Be ready to light up the match or lighter.

5. Point the fire at the mouth of the flask as soon as you see gas emerging. You should hear a small pop and see a green flame "dancing" inside the flask.

Explanation

This experiment is derived from an earlier version, wherein copper(II) chloride was used to give a single replacement redox reaction with aluminum as shown below ("Foiled Again"):

$$
2 \mathrm{Al}(\mathrm{s})+3 \mathrm{CuCl}_{2}(\mathrm{aq}) \rightarrow 2 \mathrm{AlCl}_{3}(\mathrm{aq})+3 \mathrm{Cu}(\mathrm{s})
$$

Looking at the reactivity series, we see that aluminum is more reactive than copper thus the single replacement reaction occurs. 


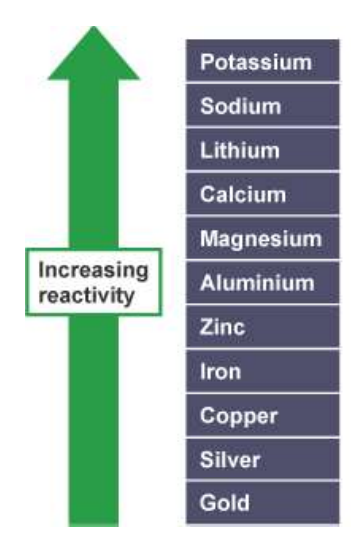

Figure 1. Reactivity Series (“f) Reactivity Series”, 2017)

At the same time, a side reaction occurs wherein free hydrogen ions from the copper(II) chloride solution, which is slightly acidic, react with aluminum to form hydrogen gas which is the same gas as the one emerging from the experiment.

$$
2 \mathrm{Al}(\mathrm{s})+6 \mathrm{H}^{+}(\mathrm{aq}) \rightarrow 2 \mathrm{Al}^{3+}(\mathrm{aq})+3 \mathrm{H}_{2}(\mathrm{~g})
$$

In this experiment, we used copper(II) sulfate instead of copper(II) chloride because copper(II) sulfate is more accessible and less costly to buy. Using this alone will not push the reaction, which is why a solution of sodium chloride was used. This is because aluminum foil has a protective oxide layer which protects the aluminum metal from further reaction with air, water or acid (Fleming). Chloride ions disrupt this layer thus allowing the aluminum-copper reaction (Nuffield Foundation and Royal Society of Chemistry) as shown below:

$$
2 \mathrm{Al}(\mathrm{s})+3 \mathrm{CuSO}_{4}(\mathrm{aq}) \rightarrow \mathrm{Al}_{2}\left(\mathrm{SO}_{4}\right)_{3}(\mathrm{aq})+3 \mathrm{Cu}(\mathrm{s})
$$

The side reaction mentioned above is also applicable. Hydrogen gas is a product in the reaction, which is proven by the small pop heard when lighted.

\section{Disposal}

- The solution may be thrown in the sink with running water. Any unreacted aluminum foil may be thrown in the trash bin.

\section{Documentation}

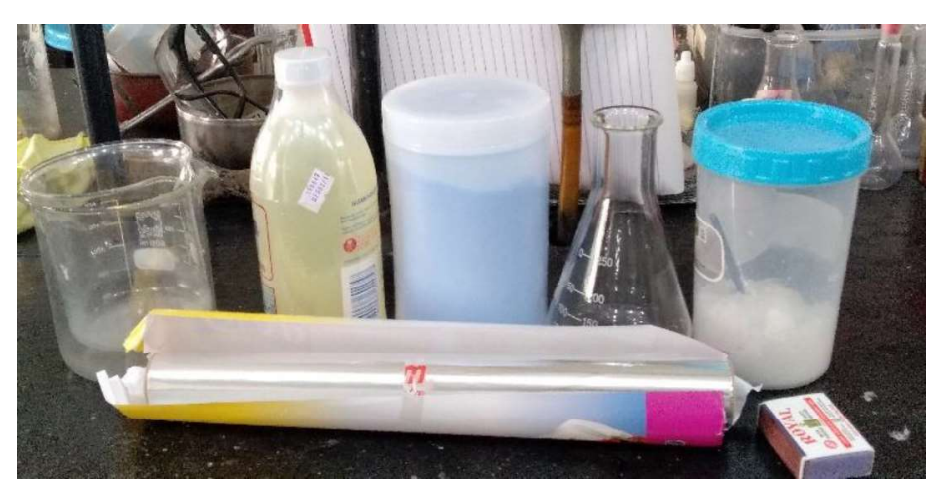

Materials used

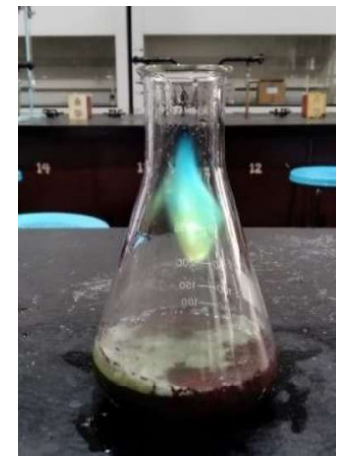

Green flame on top of dissolving aluminum 


\section{References}

1. Foiled Again [Internet]. [cited 2020 Feb 5]. Available from: https://www.flinnsci.com/foiledagain/dc95000/

2. f) Reactivity Series [Internet]. IGCSE Chemistry revision. 2017 [cited 2020 Feb 5]. Available from: https://igcsechemrevision.wordpress.com/section-2/f-reactivity-series/

3. Fleming D. Dancing flames [Internet]. RSC Education. [cited 2020 Feb 5]. Available from: https://edu.rsc.org/exhibition-chemistry/dancing-flames/2000045.article

4. The real reactivity of aluminium [Internet]. RSC Education. [cited 2020 Feb 5]. Available from: https://edu.rsc.org/resources/the-real-reactivity-of-aluminium/439.article 